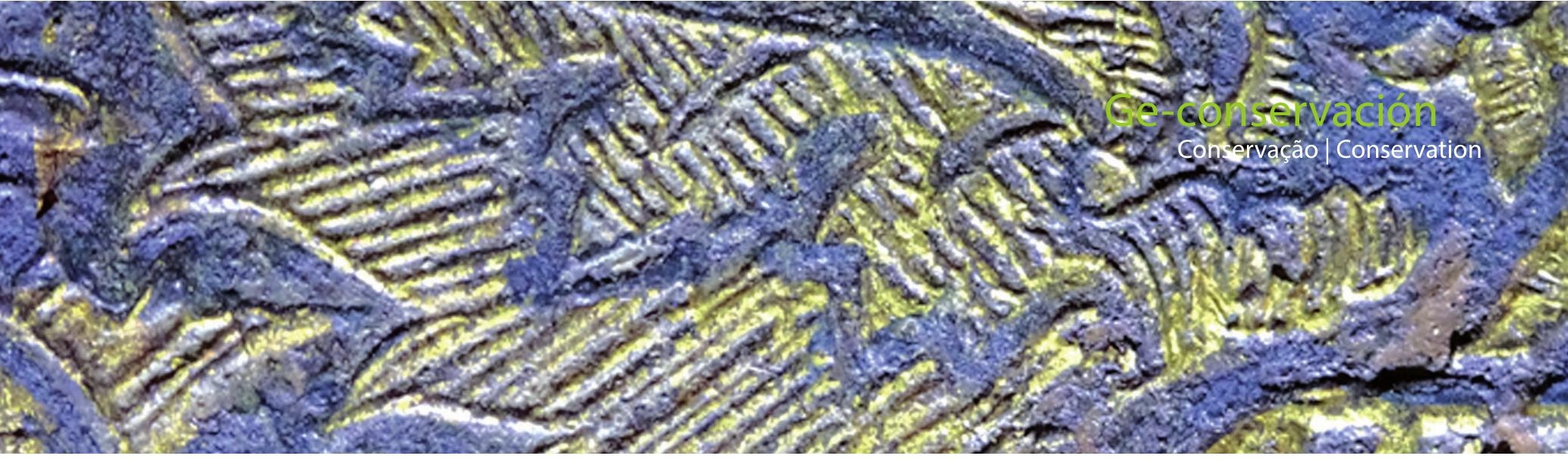

\title{
Aportación al mapa del brocado aplicado en el territorio histórico de Gipuzkoa: nuevos casos, filiación entre modelos y evolución estilística
}

Maite Barrio Olano, Ion Berasain Salvarredi, Jesús Muñiz Petralanda, Vera Aldabe Gil, Iratxe Colado García

Resumen: En este artículo se presentan tres obras escultóricas guipuzcoanas (España, País Vasco), en las que la presencia de la técnica polícroma del brocado aplicado no había sido detectada hasta la fecha. Se trata de los retablos del Oratorio de Loiola (1498-1512) y San Martin de Azpeitia (1521) y la talla de la Virgen con el Niño de Zumaia (ca.1500). El análisis de sus modelos de brocado ha motivado la revisión formal de esta técnica en el territorio, desvelando filiaciones complejas entre retablos ubicados en la región e incluso en poblaciones más lejanas. Igualmente se propone una sencilla ordenación estilística de los mismos, ya que su periodo de producción coincide con la transición de dos estilos artísticos: el tardogótico y el primer renacimiento.

Palabras clave: brocado aplicado, policromía, retablo, escultura policromada, Gipuzkoa, País Vasco, España

\section{Contribution to the map of the applied brocade in the historical territory of Gipuzkoa: new cases, affiliation between patterns and stylistic evolution}

Abstract: This article presents three sculptural works in Gipuzkoa, Spain/Basque Country), in which the presence of the polychrome technique of applied brocade had not been detected to date. These are the altarpieces of the Oratorio de Loiola (1498-1512) and San Martín de Azpeitia (1521) and the carving of the Virgin and Child of Zumaia (ca. 1500). The analysis of their brocade models has motivated the formal revision of this technique in the territory, establishing complex affiliations between altarpieces located in the region and even in more distant places. At the same time, a simple stylistic arrangement of them is proposed, because their production period coincides with the transition of two artistic styles: the late Gothic and the early Renaissance.

Keyword: Applied brocade, polychromy, altarpiece, polychromed sculpture, Gipuzkoa, Basque country, Spain

\section{Contribuição para o mapa do brocado aplicado no território histórico de Gipuzkoa: novos casos, relação entre modelos e evolução estilística}

Resumo: Este artigo apresenta três obras escultóricas de Gipuzkoa (Espanha, País Basco), nas quais, até à data, não foi detetada a presença da técnica policromada de brocado aplicado. As três obras são os retábulos do Oratório de Loiola (1498-1512) e de San Martin de Azpeitia (1521) e a talha da Virgem com o Menino de Zumaia (ca.1500). A análise dos seus modelos de brocado motivou a revisão formal desta técnica no território, revelando complexas relações entre retábulos localizados na região, e em regiões mais distantes. É proposto um arranjo estilístico simples, uma vez que o seu período de produção coincide com a transição de dois estilos artísticos: o gótico tardio e o primeiro renascimento.

Palavras-chave: brocado aplicado, policromia, retábulo, escultura policromada, Gipuzkoa, País Basco, Espanha 


\section{Introducción}

El brocado aplicado es una técnica de policromía en relieve de gran laboriosidad que permite la imitación de los lujosos textiles bordados en hilo de oro y plata del final de la Edad Media y comienzos de la Edad Moderna mediante una reproducción seriada. Fue utilizada en Europa durante los siglos $\mathrm{XV}$ y XVI, enriqueciendo el rico repertorio de decoraciones tardogóticas y renacentistas, principalmente en escultura y pintura, aunque son abundantes los ejemplos en pintura mural y piedra policromada.

En estas líneas no pretenderemos definir la técnica en sí, ni detallar sus procedimientos, cronología, contexto o variables técnicas, aspectos todos ellos estudiados anteriormente y que exceden el marco del artículo. El objetivo de este escrito es doble: por un lado, ampliar con tres nuevos casos el elenco de obras de arte con brocado aplicado en el marco geográfico de Gipuzkoa; por otro, establecer filiaciones formales entre los diversos modelos registrados, bien en el propio territorio, bien en zonas limítrofes, sugiriendo una evolución estilística de los mismos.

\section{Metodología de trabajo}

Ciertos trabajos precedentes realizados por los autores en el curso de su carrera han sido especialmente valiosos a la hora de plantear este artículo: es el caso del proyecto Guía de Retablos Esculpidos Flamencos en Euskadi ${ }^{[1]}$ y Aplicación del Método de Evaluación de Bienes Muebles del Patrimonio Religioso a la Escultura Mueble Tardogótica en Gipuzkoa [2]. Ambos nos condujeron a la revisión sistemática de un conjunto de obras que por cronología podían incluir esta técnica polícroma.

Al abordar el presente estudio, las líneas de trabajo principales han sido dos: búsqueda documental y trabajo de campo. En la primera, el eje fundamental se ha basado en la revisión bibliográfica, el estudio de informes de intervención inéditos y el contacto con ciertas empresas de conservación-restauración.

En cuanto al trabajo de campo, este ha consistido en la visita a aquellas obras con brocado aplicado que no habían sido estudiadas precedentemente: toma de fotografías generales y de detalle, con luz visible y rasante, macrofotografías e imágenes con microscopio digital, recogida de datos sobre los propios brocados y realización de dibujos y calcos.

De igual manera se examinaron de nuevo ciertas obras estudiadas anteriormente, revisando dibujos y datos. A partir de ello, se procedió a la estructuración de la información y a la realización de nuevos dibujos y gráficos siguiendo la metodología propuesta por el Grupo Europeo de Policromía en Relieve GEPR ${ }^{[3]}$ (Carrassón López de Letona et al. 2021).
Finalmente se procedió al cotejo entre modelos, lo que ha permitido la oportunidad de relacionar obras ubicadas tanto en el territorio de Gipuzkoa como en Bizkaia, Araba, Burgos, Asturias y Toledo.

\section{Antecedentes}

La primera noticia sobre la técnica del brocado aplicado en Gipuzkoa se encuentra en la tesis doctoral de Arrazola sobre el Arte del Renacimiento en este territorio, publicada en 1967. La autora transcribe el contrato firmado en 1545 por Juan de Alda, policromador del retablo de san Pedro de Bergara (Arrazola 1988: tomo 2, 402). En dicho documento se solicita el uso de "brocados de chapa", utilizando una terminología empleada en textos de la época que alude a esta técnica (Roberto 2005: 260) ${ }^{[4]}$.

En cualquier caso, la detección de brocado aplicado en Gipuzkoa ha estado ligada generalmente a operaciones de conservación-restauración. La primera vez que se certifica su utilización es durante la restauración del retablo renacentista del monasterio de Bidaurreta en Oñati (1988-89). En la publicación realizada, Berasain le dedicó un capítulo específico (Martiarena et al. 1991 6471).

En este mismo libro se señala la presencia de brocado aplicado en el retablo de san Antón de la parroquia de san Pedro de Zumaia, objeto años más tarde de un artículo (Berasain y Barrio 1998), donde a su vez se reseña su empleo en el retablo de la Coronación de la Virgen de la parroquia de la Asunción de santa María en Errenteria ${ }^{[5]}$.

A finales de esta década, durante los trabajos de restauración de los retablos de san Miguel y de la Virgen del Rosario de la parroquia de san Juan Bautista de Arrasate, la empresa Equipo 7 recoge varios ejemplos de esta técnica (Astigarraga 2000). Y en los años 2000 Artelan Restauraciones referencia nuevos casos en los retablos de la Piedad en la capilla del mismo nombre de san Miguel de Oñati y en el de san Miguel de la parroquia de san Miguel de Altzaga (Artelan Restauración 2000; Artelan Restauración 2002: 37-48).

En 2009 Rodríguez dedica su tesis doctoral a este tema. La autora se centra en cinco de los siete retablos guipuzcoanos citados e incorpora el de san Juan Bautista de la Parroquia de san Miguel de Oñati, estableciendo fichas de datos y realizando análisis de materiales de todos ellos (Rodríguez 2009).

En 2010, el estudio realizado durante la intervención del retablo de la Coronación de Errenteria permite profundizar sobre el conocimiento del brocado en esta obra (Barrio 2013: 152-158), señalando filiaciones con otros utilizados en obras bruselenses (Geelen y Steyaert 2011: 107-116). 
Posteriormente, ciertos trabajos inéditos mencionados en la introducción permitieron desvelar la presencia de brocado aplicado en otras obras, siendo precisamente estos ejemplos los que exponemos a continuación.

\section{Nuevos casos de estudio}

-Retablo de la Anunciación. 1498-1512. Oratorio de la santa Casa de Loiola. Azpeitia [figura 1]

El origen de este retablo está vinculado al cuadro de la Anunciación atribuido a Jean Provost que se incluye en su parte inferior. De acuerdo con la tradición, esta tabla fue un regalo que hizo la reina Isabel la Católica a Magdalena de Araoz, doncella que estuvo a su servicio hasta que en 1498 casó con Martín García de Loyola (Arrázola 1988: 23-27). Tras haberse atribuido a la pintura ciertos hechos milagrosos, sus propietarios decidieron construir una capilla e instalarla en un retablo que incluía el relieve de la Lamentación sobre Cristo muerto. No se conoce la fecha de su realización, pero en 1573 ya debía existir la disposición actual (Lopetegui 1945: 370).

El retablo fue repolicromado en época indeterminada, tanto a nivel de mazonería como del relieve y tallas, y en la década de 1980 fue objeto de una intervención de conservación-restauración (Martiarena 1980). A pesar de los recubrimientos posteriores, se deduce claramente que la policromía primitiva seguía los cánones de la época, con dorado bruñido, lacas rojas y veladuras verdes sobre lámina metálica, azul azurita y pequeños esgrafiados, etc. Se observan igualmente algunas aplicaciones de papel en forma de flores plateadas y corladas ( $11 \times 11 / 12 \mathrm{~mm})$, salpicadas sobre las túnicas de varios personajes.

El brocado aplicado ornamentaba originariamente los atuendos de varios personajes del retablo. Desafortunadamente, ha llegado hasta nuestros días en pésimo estado de conservación, habiéndose podido identificar únicamente cuatro modelos, dos continuos y dos aislados, ubicados todos ellos en el relieve.

La túnica de la Virgen luce un brocado continuo incompleto, que podemos describir gracias a la similitud con otras obras. De placa rectangular, es dorado, con realces en azul que subrayan líneas del dibujo y rellenan ciertos campos lisos. El relieve marca los contornos de las formas y los nervios de las hojas, haciendo vibrar el oro con estrías multidireccionales [figura 2].

María Magdalena, a su vez, deja adivinar bajo un grueso repinte una sucesión de motivos sinuosos que corresponden sin lugar a dudas a un modelo de esta técnica. La comparación con otros modelos nos permitirá su identificación.

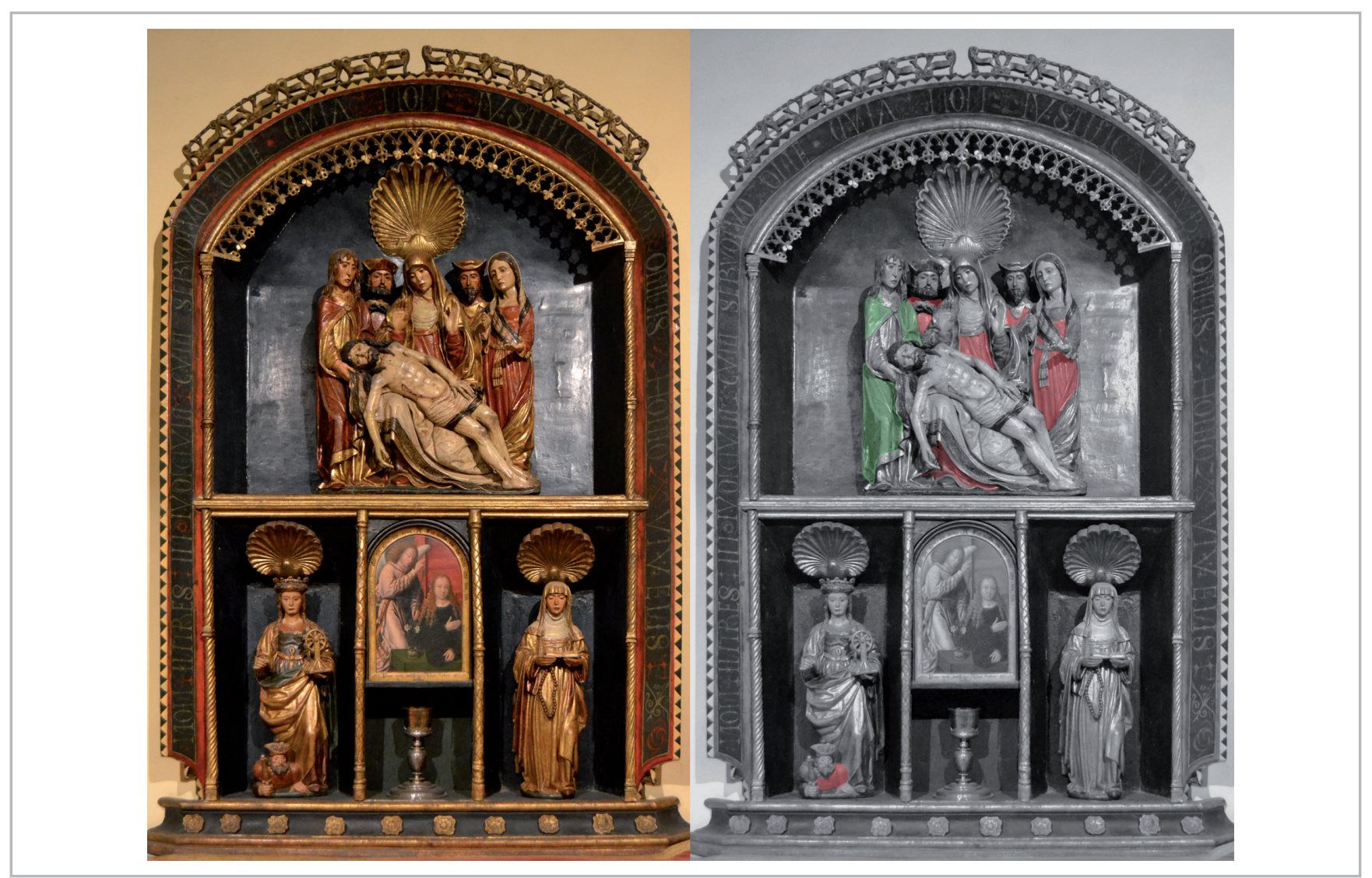

Figura 1.- Retablo de la Anunciación de Loiola. Conjunto y localización de los campos decorados con brocado aplicado, en rojo con motivos yuxtapuestos y en verde aislados. 

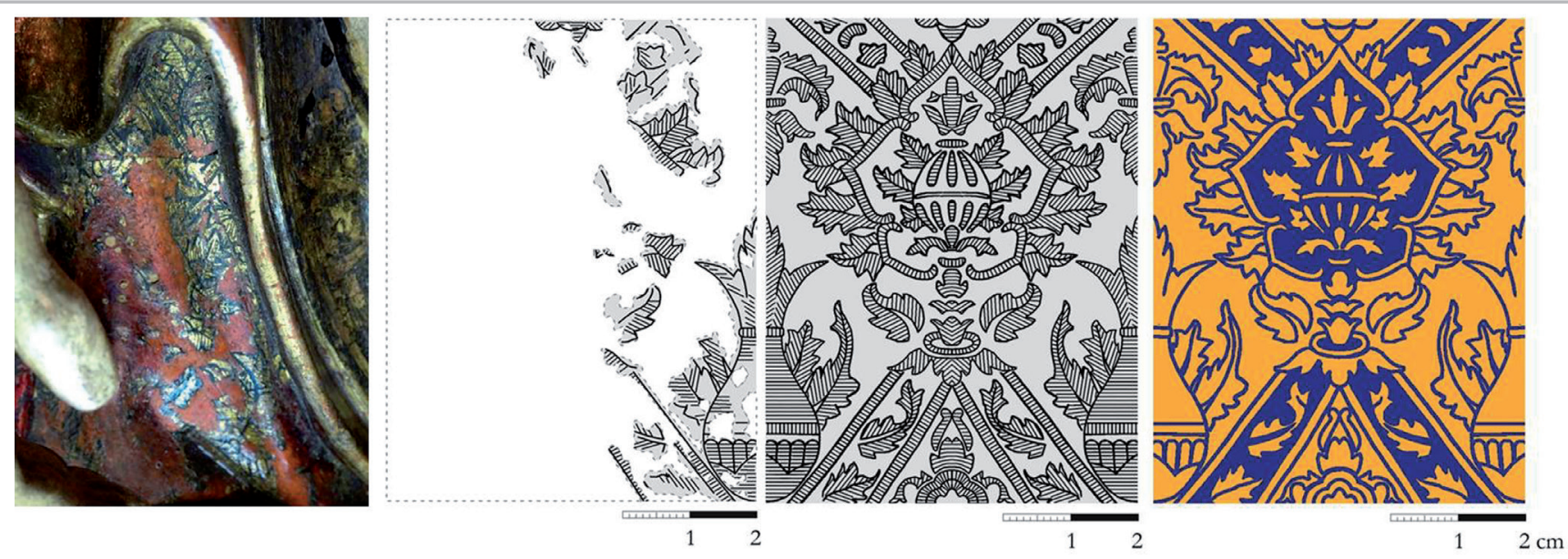

Figura 2.- Brocado aplicado continuo de la túnica de la Virgen del Retablo de Loiola, 7,2 x 5,5 cm y 12 estrías por cm. De izquierda a derecha fotografía, dibujo de calco, gráfico hipotético de relieve, gráfico hipotético de color.
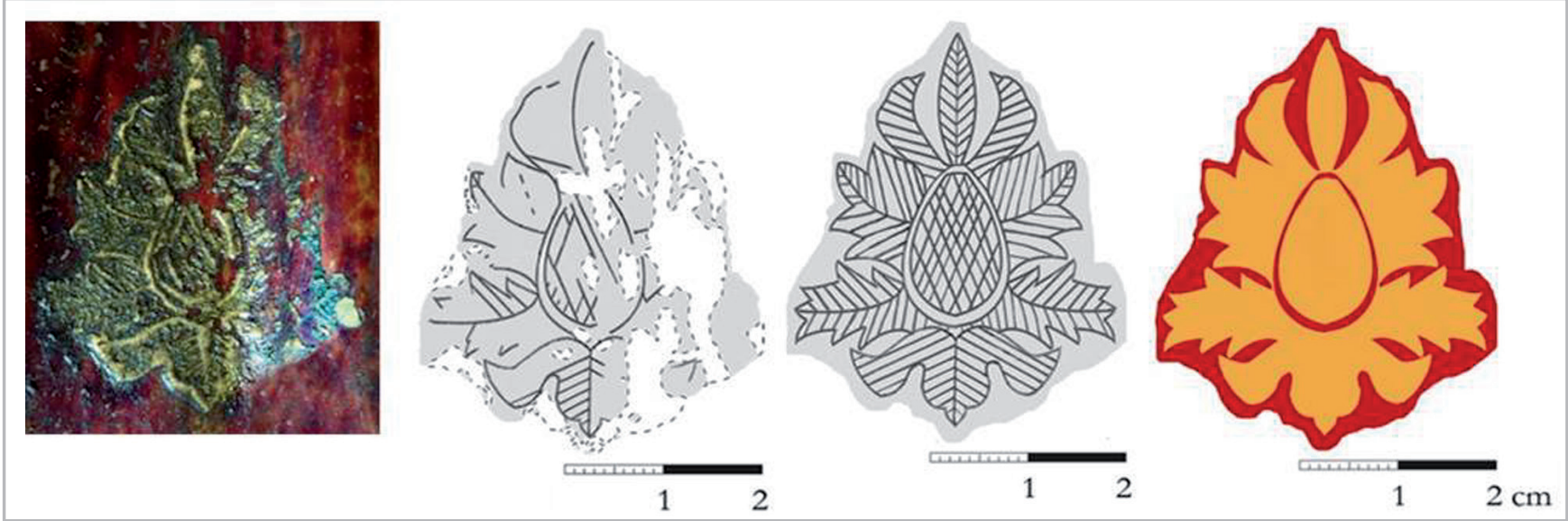

Figura 3.- Brocado aplicado aislado de la túnica de San Juan. Retablo de la Anunciación de Loiola. 3,4 x 2,8cm y 12 estrías por cm. De izquierda a derecha fotografía, dibujo de calco, gráfico hipotético de relieve, gráfico hipotético de color.

Por su parte, el manto de san Juan está decorado con dos brocados aplicados aislados. El mayor consiste en un despliegue vegetal, con un cogollo central del que surgen un conjunto de hojas. Es dorado, con relieve en el dibujo de las formas y estriado en varias direcciones [figura 3]. Queda una huella en la laca $(1,3 \times 1,8 \mathrm{~cm})$, de forma circular achatada con pequeños fragmentos dorados que remite a la presencia de otro brocado aislado de menor tamaño.

\section{- Retablo de san Martin. 1521. Iglesia de san Sebastián de} Soreasu, Azpeitia

Martín de Zurbano, miembro del Consejo Real, obispo de Tuy y presidente del tribunal de la Inquisición, dispuso en su testamento en 1516 la construcción de una capilla para ubicar su sepulcro y un retablo dedicado al santo Obispo (Odriozola 1993: 69-73). Las obras comenzaron en 1517 , terminándose en 1520 . El retablo es obra de Johan de París y Antonio de Piniel, tal y como testimonia el contrato firmado el 26 de febrero de 1521 (Arrázola 1988:
16-17 ${ }^{[6]}$, finalizándose el mismo año. Está dedicado a la Pasión de Jesús, con san Martin en la imagen titular.

En esta pieza conviven la tradición artística nórdica con un incipiente conocimiento del Renacimiento, carácter hibrido muy propio de su cronología. Actualmente las esculturas y los relieves se hallan colocados sobre una estructura de mármol a modo de fondo. La mazonería del retablo se perdió en un momento indeterminado de su historia, si bien hasta la drástica intervención de comienzos de los años 80 , el retablo conservaba una arquitectura presuntamente inspirada en la original (Odriozola 1993: 69-73).

El documento del contrato es bastante preciso en lo relativo a la iconografía del retablo, sus medidas y coste. Sin embargo, no aborda detalles sobre la policromía, salvo una disposición muy genérica que pretendía garantizar la calidad de ejecución: "Yten asimismo el oro y la pintura fuese muy fino, qual devia ser para tal obra"[7].

La policromía que hoy apreciamos es confusa y corresponde al momento de la eliminación de la última mazonería. Se 

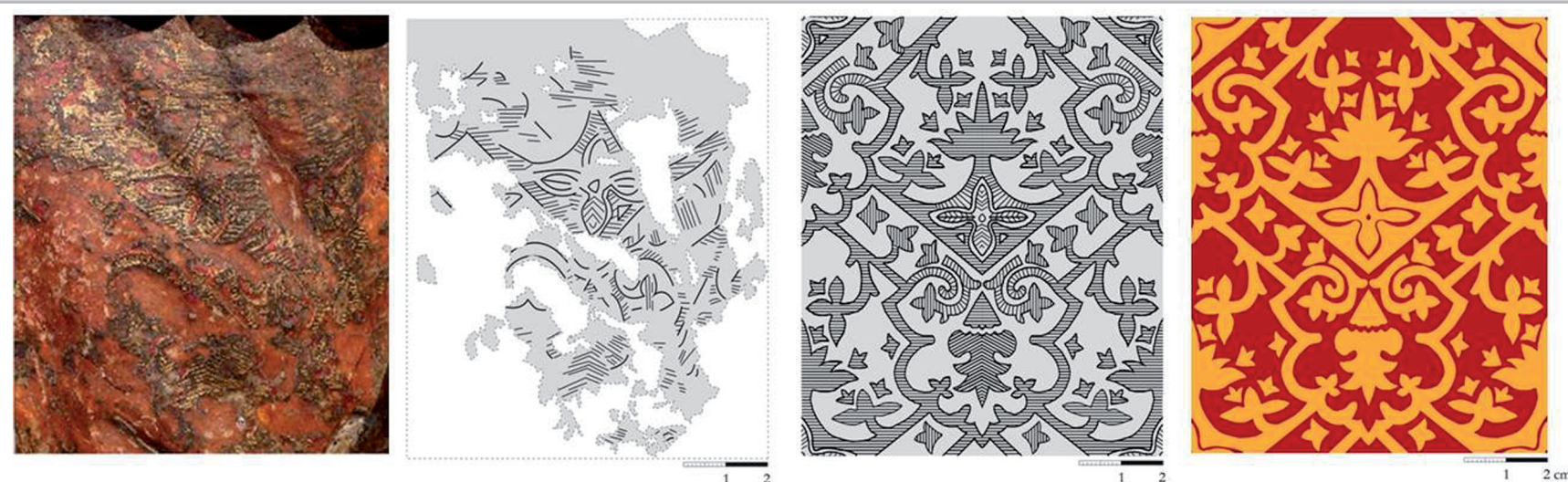

Figura 4.- Brocado aplicado continuo. Túnica de Pilatos, relieve del Juicio de Jesús. Retablo de San Martin, Azpeitia. 10,5 x 8,6 cm, 13 estrías por $\mathrm{cm}$. De izquierda a derecha fotografía, dibujo de calco, gráfico hipotético de relieve, gráfico hipotético de color.

pueden observar al mismo nivel fragmentos originales, amplios repintes de la última intervención y restos de una repolicromía precedente en tonos pasteles que se eliminó de manera parcial. Bajo la suciedad y pátinas artificiales, se percibe que el colorido primitivo seguía los patrones habituales de la época, con aplicaciones varias, esgrafiado en azul, rojo y blanco y brocado aplicado.

Con respecto a este último, se han observado tres modelos, si bien es probable que en origen hubiera más. Entre los yuxtapuestos sobresale la decoración de la túnica de Pilatos [figura 4]. De placa rectangular, relieve en las líneas del dibujo, rayado paralelo en varias direcciones, dorado y realces en rojo en las zonas lisas.

En peor estado de conservación se encuentra el modelo del manto de Cristo en el mismo relieve. Los fragmentos existentes revelan un dibujo similar al hallado en la túnica de la Virgen de Loiola, esta vez de dimensiones superiores y con realces en rojo.

Un ejemplo de brocado aplicado aislado se ubica en el relieve de El Camino del Calvario, sobre la túnica de Cireneo [figura 5]. Dispuesto sobre laca roja, es de contorno cuadrilobulado, con los lóbulos superior e inferior en forma de arco conopial. La banda que define el perfil alberga un círculo y cuatro semiesferas irregulares. El relieve, aplanado parcialmente, es patente en los perfiles de las formas y en el rayado en varias direcciones. El brocado ha sido dorado y realzado en los campos lisos con laca roja.

\section{-Virgen con Niño, ca 1500. Zumaia}

Esta escultura de la Virgen con el Niño, de principios del s. XVI, probablemente fue la imagen titular de un altar dedicado a Nuestra Señora, uno de los ocho existentes en la iglesia por aquella época (Odriozola 1998: 222).

La primera mención de la talla la proporciona el Padre Lizarralde (Lizarralde 1926: 126, grab. 71), quien la describe presidiendo un retablo colateral de 1828 diseñado por Pedro José de Urquiola, hoy desaparecido y la califica como una "escultura flamenca del siglo XV". Un año más tarde G. Weise la consideraba una peculiar variación de las influencias neerlandesas, incluyéndola en un breve listado de piezas valiosas (Weise 1927, II: 87-88); valoración
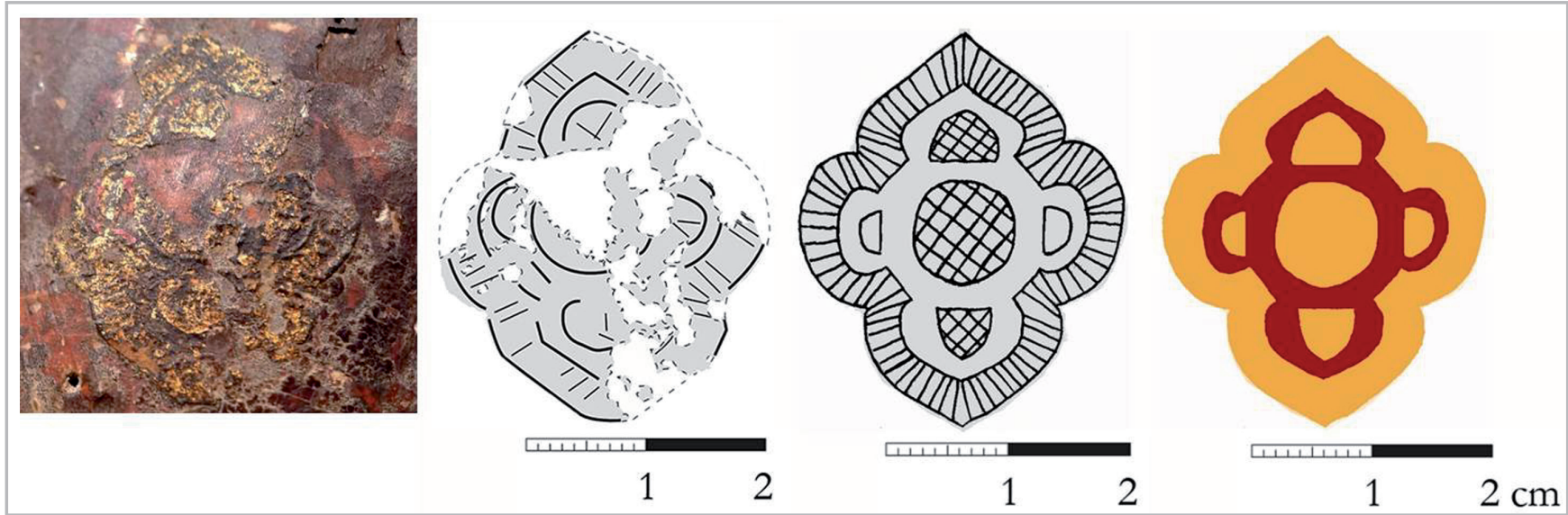

Figura 5.- Brocado aplicado aislado. Retablo de san Martin, Azpeitia. $3,3 \times 2,7 \mathrm{~cm}, 10$ estrías por cm. De izquierda a derecha fotografía, dibujo de calco, gráfico hipotético de relieve, gráfico hipotético de color 
positiva y origen foráneo que con alguna variante se ha repetido en las breves reseñas posteriores.

Destaca en esta escultura la caracterización de sus personajes. La fisonomía de la Virgen se asemeja a la de una talla de santa Bárbara de la catedral de san Quintín de Hasselt (Bélgica), donde acaso debería buscarse su origen. Podría fecharse en torno al año 1500.

Su policromía original está oculta por una intervención del siglo XVII. Bajo el estofado barroco de la túnica de la Virgen, la superficie permite adivinar, entre otras técnicas de aplicación, el relieve inconfundible del brocado aplicado continuo. Lamentablemente se halla en un estado demasiado fragmentario como para reconocer el motivo representado.

\section{Relación entre modelos de brocado aplicado}

El examen de estos nuevos casos ha permitido vislumbrar ya ciertas coincidencias entre ellos. Si además se amplía el análisis a los modelos detectados hasta la fecha en Gipuzkoa, las relaciones se incrementan, percibiéndose filiaciones claras entre motivos localizados en diversos retablos de este territorio e incluso de zonas limítrofes.

En este texto se van a establecer comparaciones entre modelos muy similares o incluso idénticos. La comparación partirá siempre desde Gipuzkoa hacia el exterior, no abordando las relaciones que pudieran existir entre retablos no guipuzcoanos; tampoco se plantea la clasificación del repertorio completo de motivos utilizados en Gipuzkoa, sino solamente de aquellos repetidos en varios retablos.

Las obras aludidas corresponden a retablos escultóricos de madera policromada. Estilísticamente pertenecen al periodo tardogótico y al primer renacimiento, lo que servirá de punto de partida para trazar una hipótesis de ordenación de los modelos de brocado continuo.

\section{- A) Modelos con decoración vegetal estructurada en red}

Los motivos que incluimos en este apartado muestran diseños que, una vez colocados de forma yuxtapuesta, crean una malla o red continua. Dicha trama es predominantemente ojival o romboidal, con figuras polilobuladas o formas conopiales que alojan un conjunto variado de flores, hojas, palmetas y frutos. Este tipo de modelos podrían incluirse en el término genérico "patrón de granada", creado en el siglo XIX para describir una variedad de formas naturales estilizadas, tales como la piña, la alcachofa, el cardo, el loto y la palmeta (Bonito 1994: 193).

Se trata de un patrón muy habitual y su uso como elemento ornamental ha sido muy dilatado en el tiempo, perdurando en pinturas y esculturas europeas durante más de siglo y medio a pesar de los cambios de moda y gustos sociales. Extensión aplicable también a diversos ámbitos geográficos y diferentes manufacturas artísticas.

Son diseños ornamentales utilizados en los ricos terciopelos y sedas bordados con hilos de oro de las vestimentas y ornamentos litúrgicos de esta época, que el brocado aplicado pretende emular con gran realismo. Según los estudiosos, su origen se situaría en Oriente. Ya en el siglo XIII Italia importaba sedas de Bizancio, ampliando posteriormente el mercado a Oriente próximo y Egipto, Ilegando a Asia central y Oriente medio. Al mismo tiempo, a partir del XIV, Italia produciría motivos propios basados en los anteriores. En su realización colaboraron a menudo pintores, bordadores, diseñadores textiles y tejedores (Borgioli 2011: 65-66) y sus modelos se divulgaron a través de libros utilizados por bordadores y pintores

Los modelos presentados aquí con decoración vegetal en red son el 1, 2 y 3 [ver tablas 1 y 2 ]

\section{- Modelo nº 1}

Presente en:

- Retablo de la Anunciación. santa Casa de Loiola. Azpeitia. 1498-1512.

- Retablo de san Martín. Iglesia de san Sebastián de Soreasu. Azpeitia. 1521.

- Retablo Mayor. Iglesia Basílica de santa María. Llanes. 1517.

El modelo no es idéntico en los tres retablos, aunque sí muy similar, cambiando las decoraciones de ciertos elementos en gallones (Loiola) por formas de tipo foliáceo (Llanes). En ambos casos se ha seguido el mismo sistema de policromado: los campos lisos de la forma central y bandas bifurcadas están coloreados, mientras que en el resto de la placa sólo se pintan los perfiles de las formas.

\section{- Modelo n² :}

- Retablo de la Anunciación. santa Casa de Loiola. Azpeitia. 1498-1512.

- Retablo Mayor. Iglesia san Juan Bautista. Aspuru. Álava. 1515-1520.

- Retablo Mayor. Iglesia Basílica de santa María. Llanes. 1517.

Una serie de arcos enlazados crea una estructura romboidal concatenada que alberga hojas y frutos fuertemente esquematizados. En Loiola, a pesar de encontrarse embebido bajo un espeso repinte, se aprecia la doble cinta que configura el perfil del motivo y el remate del mismo. Aspuru y Llanes son muy similares, con ciertas variaciones, como el elemento en forma de rombo, 
Tabla 1.- Modelos de brocado aplicado continuo

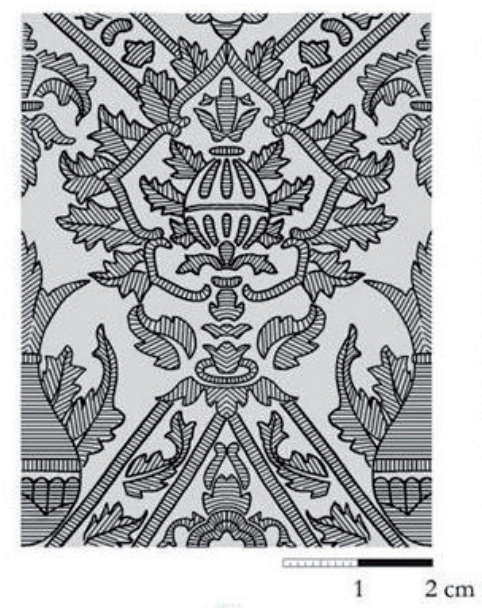

1

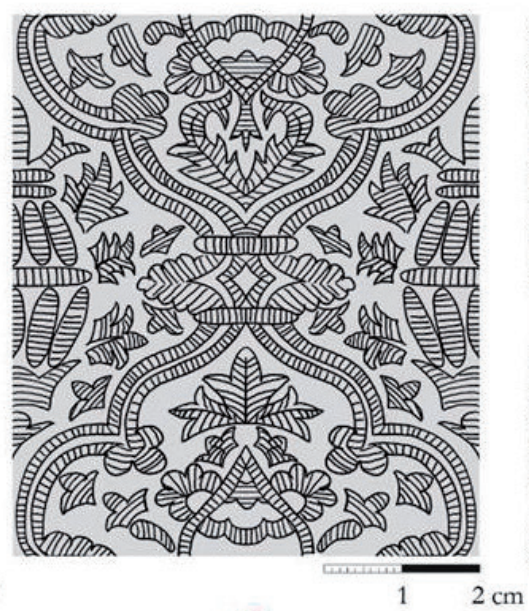

2

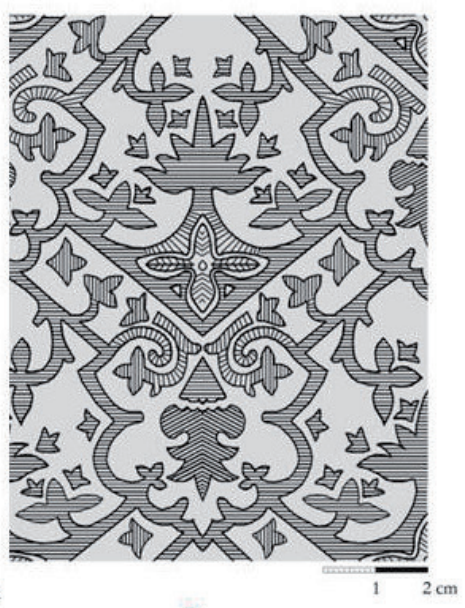

3

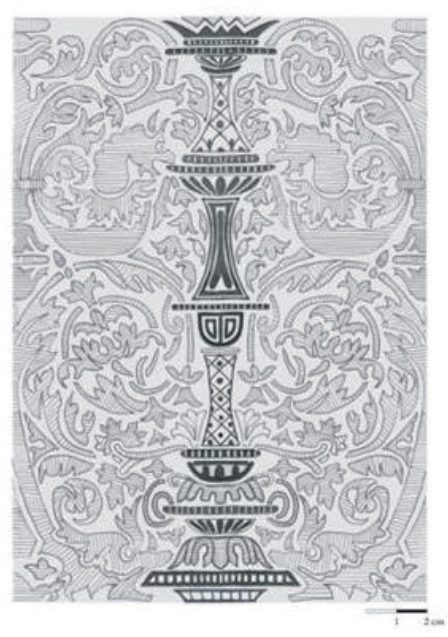

4

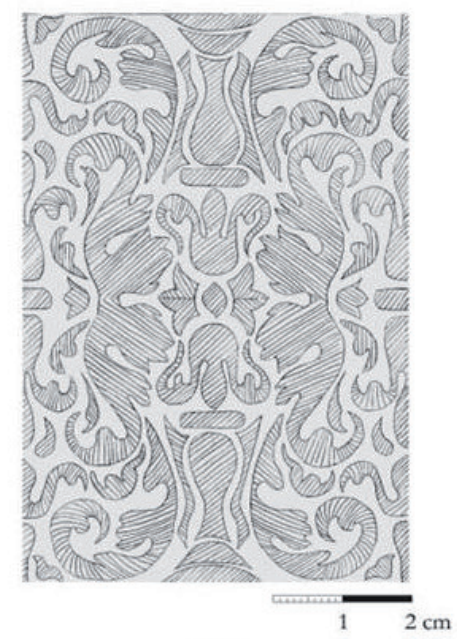

6

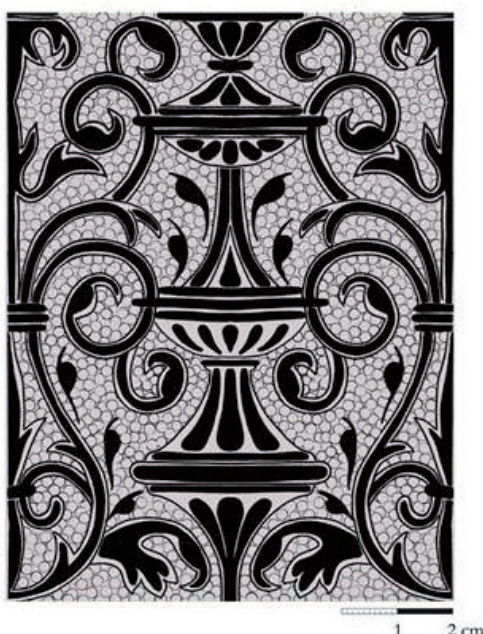

5

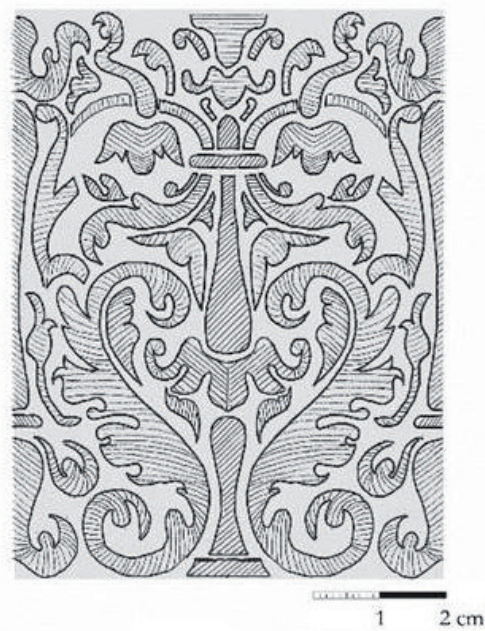

7 
Tabla 2.- Relación de retablos con modelos de brocado coincidentes. En amarillo, los similares, aunque con alguna variación. En verde los iguales. En rojo, los que pueden provenir de la misma placa. Con fondo gris los retablos pertenecientes a Gipuzkoa.

\begin{tabular}{|c|c|c|c|c|c|c|c|c|c|c|c|c|c|}
\hline & \multicolumn{7}{|c|}{ MODELOS CONTINUOS } & \multicolumn{6}{|c|}{ MODELOS AISLADOS } \\
\hline & 1 & 2 & 3 & 4 & 5 & 6 & 7 & 8 & 9 & 10 & 11 & 12 & 13 \\
\hline $\begin{array}{l}\text { Retablo de la Anunciación. Oratorio de la Santa Casa } \\
\text { de Loiola. Azpeitia. 1498-1512. }\end{array}$ & $\sqrt{ }$ & & & & & & & & & & & & \\
\hline $\begin{array}{l}\text { Retablo Mayor de Santa María. Parroquia de Santa } \\
\text { María. Lekeitio. 1507?-1514. Autores: Juan García de } \\
\text { Crisal, Pierres de Plumason, Chordon. }\end{array}$ & & & $\checkmark$ & $\checkmark$ & & & & & & & & & \\
\hline $\begin{array}{l}\text { Retablo Mayor. Iglesia San Juan Bautista. Aspuru } \\
\text { 1515-1520 Banco: atrib. taller Lope de Larrea y Ercilla. }\end{array}$ & & & & & & & & & & & & & \\
\hline $\begin{array}{l}\text { Retablo Mayor. Iglesia Basílica de Santa María. Llanes. } \\
1517 \text { Escultor: atrib. Felipe de Bigarny. Policromador: } \\
\text { atrib. Andrés de Espinosa. }\end{array}$ & $\checkmark$ & $\sqrt{ }$ & & & & & & & $\sqrt{ }$ & $\checkmark$ & $\sqrt{ }$ & $\checkmark$ & $\checkmark$ \\
\hline $\begin{array}{l}\text { Retablo de San Martin. Iglesia de San Sebastián de } \\
\text { Soreasu. Azpeitia. 1521. Autor: Johan de Paris, } \\
\text { Antonio de Piniel. }\end{array}$ & $\checkmark$ & & & & & & & & & & & & \\
\hline $\begin{array}{l}\text { Retablo de los Santos Emeterio y Celedonio. } \\
\text { Parroquia de los Santos Emeterio y Celedonio de } \\
\text { Goikolegea. Larrabetzu. 1520-25. }\end{array}$ & & & & $\checkmark$ & & & & & & & & & \\
\hline $\begin{array}{l}\text { Retablo de San Antón. Parroquia de San Pedro. } \\
\text { Zumaia. 1520-25. }\end{array}$ & & & & $\checkmark$ & & & & $\sqrt{ }$ & & & & & \\
\hline $\begin{array}{l}\text { Retablo de San Bartolomé. Parroquia de San } \\
\text { Bartolomé. Olano. } 1525 .\end{array}$ & & & $y$ & & & & & & & & & & \\
\hline $\begin{array}{l}\text { Retablo de San Martín Obispo. Parroquia de San } \\
\text { Martín Obispo. Arrieta. H.1525. }\end{array}$ & & & & $\checkmark$ & & & & & & & & & \\
\hline $\begin{array}{l}\text { Retablo mayor. La Puebla de Arganzón. H. 1531-1536. } \\
\text { Traza: atrib. Felipe de Bigarny Entalladores: Juan de } \\
\text { Ruan, Juan Matinez de Ayala; Policromador: Atrib. } \\
\text { Diego de Torres. }\end{array}$ & & & & & & & & & & & & & \\
\hline $\begin{array}{l}\text { Retablo del Monasterio de Bidaurreta. Oñati. } 1533 . \\
\text { Autor: Juan Martínez de Olazarán. }\end{array}$ & & & & & & & & & & & & & \\
\hline $\begin{array}{l}\text { Retablo de la Piedad. Parroquia de San Miguel de } \\
\text { Oñati. 1533-37. Traza: Gaspar de Tordesillas. } \\
\text { Entalladores: Andrés de Mendiguren, Miguel de } \\
\text { Iragorri y Juan de Olazarán, Juan de Ayala II pintor. } \\
\text { Policromador: Andrés de Espinosa. }\end{array}$ & & & & & & & & & & $\checkmark$ & $\sqrt{ }$ & $\sqrt{ }$ & \\
\hline
\end{tabular}

liso en Aspuru y estriado en Llanes. En ambos casos el tratamiento de policromado ha sido similar, perfilando las formas, en azul en Aspuru, en rojo en Llanes.

\section{- Modelo n³}

- Retablo de san Martín. Iglesia de san Sebastián de Soreasu. Azpeitia. 1521.

- Retablo Mayor de santa María. Parroquia de santa María. Lekeitio. Bizkaia. 1507?-1514.

- Retablo de san Bartolomé. Parroquia de san Bartolomé. Olano. Álava. 1525.
El modelo no es idéntico en los tres casos. El de Azpeitia es el más decorado, mientras que Lekeitio tiene menos follaje y en Olano ha sido simplificado en gran medida. Cabe destacar que el mismo motivo se ha reconocido en el retablo mayor de la Catedral de Toledo (1498-1504), muy similar en dibujo y dimensiones a Lekeitio.

Los modelos de brocados 1, 2 y 3, inspirados en modelos textiles decoran preferentemente las vestimentas de los personajes de relieves y esculturas, aunque en algunos casos cubren paneles de cajas (Llanes) o fondos de pinturas (Olano). Comparten tramas simétricas y repetitivas [figura 6], enriquecidas por una intrincada 

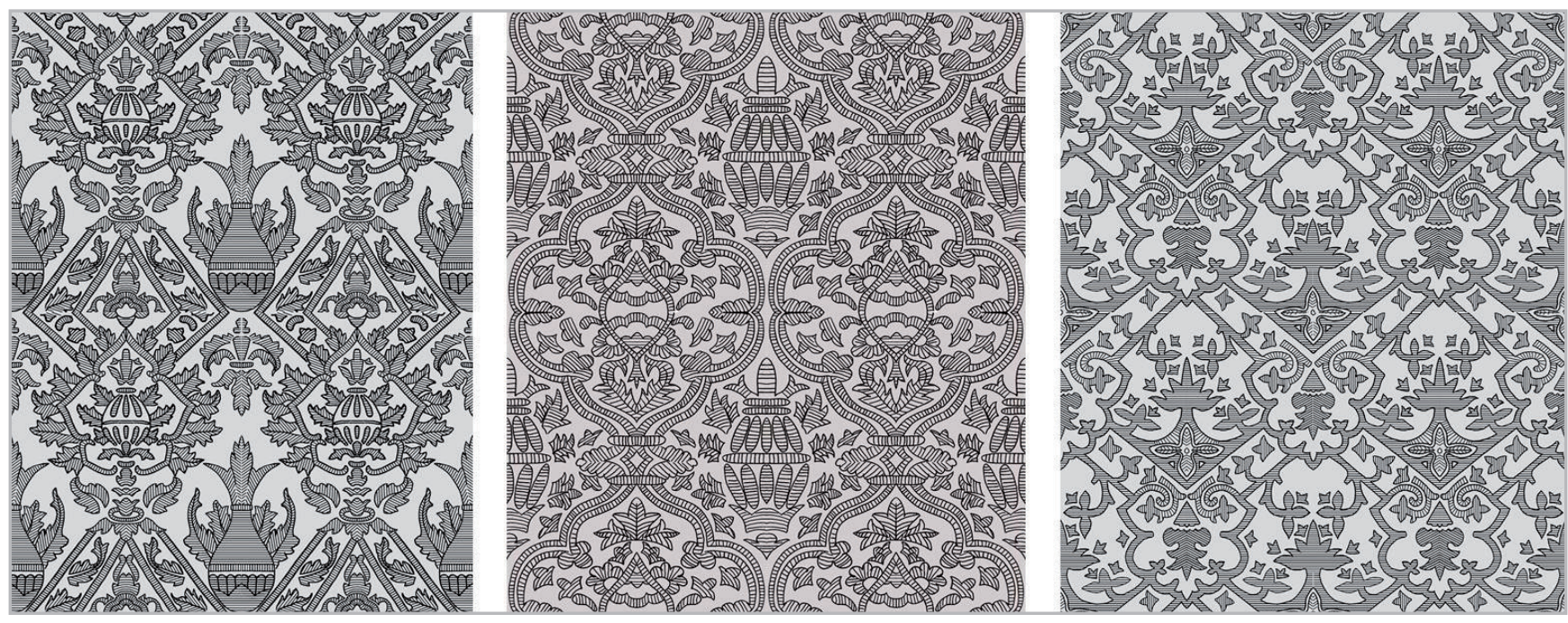

Figura 6.- Modelos 1, 2 y 3 en mosaico de 4 placas

decoración vegetal. Su ejecución oscila desde un carácter lineal y esquemático (modelo 3) a otros más carnosos o naturalistas (modelo 1), lo que sugiere a su vez una evolución estilística.

\section{-B) Modelos Renacentistas "del romano" o "a la antigua"}

Estos ejemplos responden a motivos derivados de la ornamentación utilizada en algunos edificios clásicos de la Roma antigua. Se trata de grutescos, combinación de elementos vegetales, animales, figuras humanas y fantásticas, vasijas, balaustres, etc. dispuestos a candelieri es decir, organizados simétricamente a ambos lados de una espiga central como los brazos de un candelabro. Estos grutescos tempranos se relacionan concretamente con la decoración realizada por Pinturicchio en las estancias Borgia del Vaticano, difundida en el norte de Italia por Morto da Feltre a partir de 1492 y generalizada en Europa bajo la denominación de "lombardos" (Echeverría 1990: 140).

\section{- Modelo n4}

- Retablo de san Antón. Parroquia de san Pedro. Zumaia. 1520-25.

- Retablo Mayor de santa María. Parroquia de santa María. Lekeitio. 1507?-1514.

- Retablo de los santos Emeterio y Celedonio. Parroquia de Goikolegea. Larrabetzu. 1520-25.

- Retablo de san Martín Obispo. Parroquia de san Martín Obispo. Arrieta. H. 1525.

Una superposición de copas de bases gallonadas coronadas en un flamero sirve de eje central para desplegar a ambos lados hojas y tallos entrelazados combinados con cabezas de caballos y tritones que rellenan profusamente el espacio.

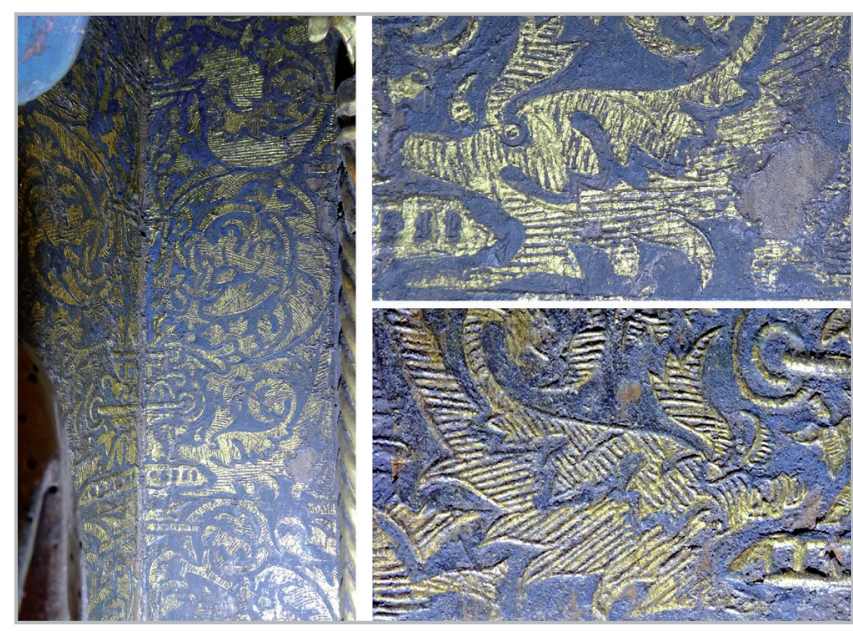

Figura 7.- Modelo 4, retablo de san Antón de Zumaia. Detalle del estriado en los tritones

En Zumaia, Arrieta y Larrabetzu el brocado presenta unas dimensiones de 19,5 x 13,8, relieve en los contornos de las formas y estrías en su interior, con una densidad máxima de $12 \mathrm{l} / \mathrm{cm}$. Destaca el volumen del elemento central. Además de otros detalles, la singularidad de la distribución de las líneas del tritón, idéntica en los tres retablos, sugiere la hipótesis de haber sido realizados a partir de la misma matriz [figura 7]. En el caso de Lekeitio, la placa en cambio es más ancha y el balaustre central está decorado diferentemente.

En todos los casos se refuerzan las formas mediante realces en color aplicados en los campos lisos, en azul, rojo, blanco o verde ${ }^{[8]}$. ; aunque existen algunos ejemplos bicolores. En Zumaia, el brocado de la túnica de un personaje de la Flagelación combina en la misma placa franjas horizontales doradas con realces de laca roja con otras no doradas coloreadas en verde ${ }^{[9]}$. En Arrieta en los laterales de las cajas del banco se divide la placa en diagonal en dos secciones contrastadas, una en blanco, la otra en azul (Muñiz y Yaniz 2020:105) ${ }^{[10]}$. 
Los retablos de Zumaia y Lekeitio, más allá de la utilización de este modelo, presentan claras similitudes en el tratamiento general de la policromía, tanto en el colorido y pequeñas aplicaciones, como en la repetición de otro patrón de granada ejecutado esta vez no con brocado aplicado sino pintado sobre lámina plateada en los fondos de las hornacinas.

\section{- Modelo n5}

- Retablo de san Antón. Parroquia de san Pedro. Zumaia. 1520-25.

- Retablo de los santos Emeterio y Celedonio. Parroquia de Goikolegea. Larrabetzu. 1520-25.

- Retablo de san Martín Obispo. Parroquia de san Martín Obispo. Arrieta. H. 1525.

Este modelo, de gran elegancia y relieve pronunciado, desarrolla a partir de un motivo central una serie de vástagos vegetales muy estilizados, en una configuración de roleos. Los campos lisos de fondo se encuentran grabados mediante un ojeteado de pequeños círculos vaciados, practicados con un punzón sobre la matriz del brocado.

La placa mide $10,7 \times 8,1 \mathrm{~cm}$, y en ninguno de los ejemplos se ha aplicado color para el acabado final, dejando la lámina de oro vista. Es de destacar que, al igual que en el anterior brocado, la matriz empleada parece ser la misma, ya que la irregularidad del trabajo manual del punzón se repite con exactitud en los tres ejemplos.

Esta coincidencia en la matriz de los motivos 4 y 5 en los tres retablos podría indicar una misma autoría a nivel de policromador o taller, o al menos la utilización de una placa heredada, vendida o compartida. Desafortunadamente, nada se conoce sobre los autores de estas obras. Muñiz destaca parecidos formales a nivel de encasamentos y dimensiones de personajes (Muñiz y Yaniz 2020:110), lo que tal vez denota una filiación más allá de la policromía, que en general se muestra con mayor presencia de esgrafiados y menos aplicaciones en Arrieta que Zumaia.

\section{- Modelo n6}

- Retablo renacentista. Monasterio de Bidaurreta. Oñati. 1533.

- Retablo mayor de La Puebla de Arganzón. H. 15311536.

El esquema compositivo de este grutesco de 8,6 x 5,6 cm. se articula respecto a un doble eje ortogonal, de forma que el motivo se repite simétricamente tanto vertical como horizontalmente. Salvo mínimos elementos que hacen referencia a jarrones, la casi totalidad del espacio se encuentra ocupada por elementos vegetales rizados sobre sí mismos. El relieve marca el contorno de las formas, con rayado en diferentes direcciones (16 estrías por $\mathrm{cm}$ ) y realces en laca roja, azul y blanco. A pesar de compartir la misma factura, no se puede asegurar que se haya utilizado la misma matriz en ambas obras.

- Modelo no7

- Retablo renacentista. Monasterio de Bidaurreta. Oñati. 1533.

- Retablo mayor de La Puebla de Arganzón. H. 15311536.

Una suerte de jarrón fitomórfico centra simétricamente el desarrollo de una serie de hojas de acanto carnosas y otros vegetales que se entrelazan ocasionalmente. El motivo $(9 x$ $6,5 \mathrm{~cm}$ ) ha sido realizado con contornos y estrías en relieve, 15 por $\mathrm{cm}$, y realces de color en rojo y blanco.

La utilización de los modelos 6 y 7 en estos retablos pudiera ser significativa. Pertenecientes ambos al primer renacimiento, la realización del primero corrió a cargo de Juan Martínez de Olazarán, natural de Oñati, nombrado como entallador o pintor en la documentación (Martiarena et al. 1991: 16-28). En Arganzón, cuya traza ha sido atribuida a Bigarny, la policromía podría deberse al pintor Diego de Torres, vecino de Burgos (Echeverría y Vélez 2011:104). Ningún dato hasta el momento permite establecer más conexiones, más allá de una policromía similar, de arquitectura dorada, blanca y azurita, timidez en el uso de esgrafiados (más abundantes en Bidaurreta), motivos con troquel dorados a la sisa y decoración a pincel negra y roja en los paños blancos.

A pesar de constituir en su origen una ornamentación arquitectónica, este tipo de motivos a la romana decoraron igualmente los textiles de las vestimentas y ornamentos litúrgicos de esta época, conservándose ejemplos en iglesias $^{[11]}$ y museos. En cuanto a su reproducción en brocado aplicado en los retablos, ornamentaron tanto fondos de caja (Zumaia, Arrieta, Arganzón, Larrabetzu, Lekeitio), como vestimentas y textiles (Zumaia, Arrieta, Bidaurreta). Parece apreciarse un ligero desplazamiento en la preferencia de localización en las cajas laterales, aunque para poder afirmarlo debería hacerse un análisis de un número mayor de casos.

\section{- Modelos aislados [ver tablas 2 y 3]}

En el grupo de brocados aislados se detectan igualmente numerosas filiaciones. Se trata de diseños vegetales, preferentemente ramilletes de hojas, flores, etc. o figurativos, en forma de cruces, jarrones o similares.

El modelo presentado en Azpeitia [figura 5] decora los retablos Zumaia y Lekeitio. A su vez, la Piedad de Oñati posee al menos 5 brocados aislados similares a los que 
Tabla 3.- Modelos de brocado aplicado aislado

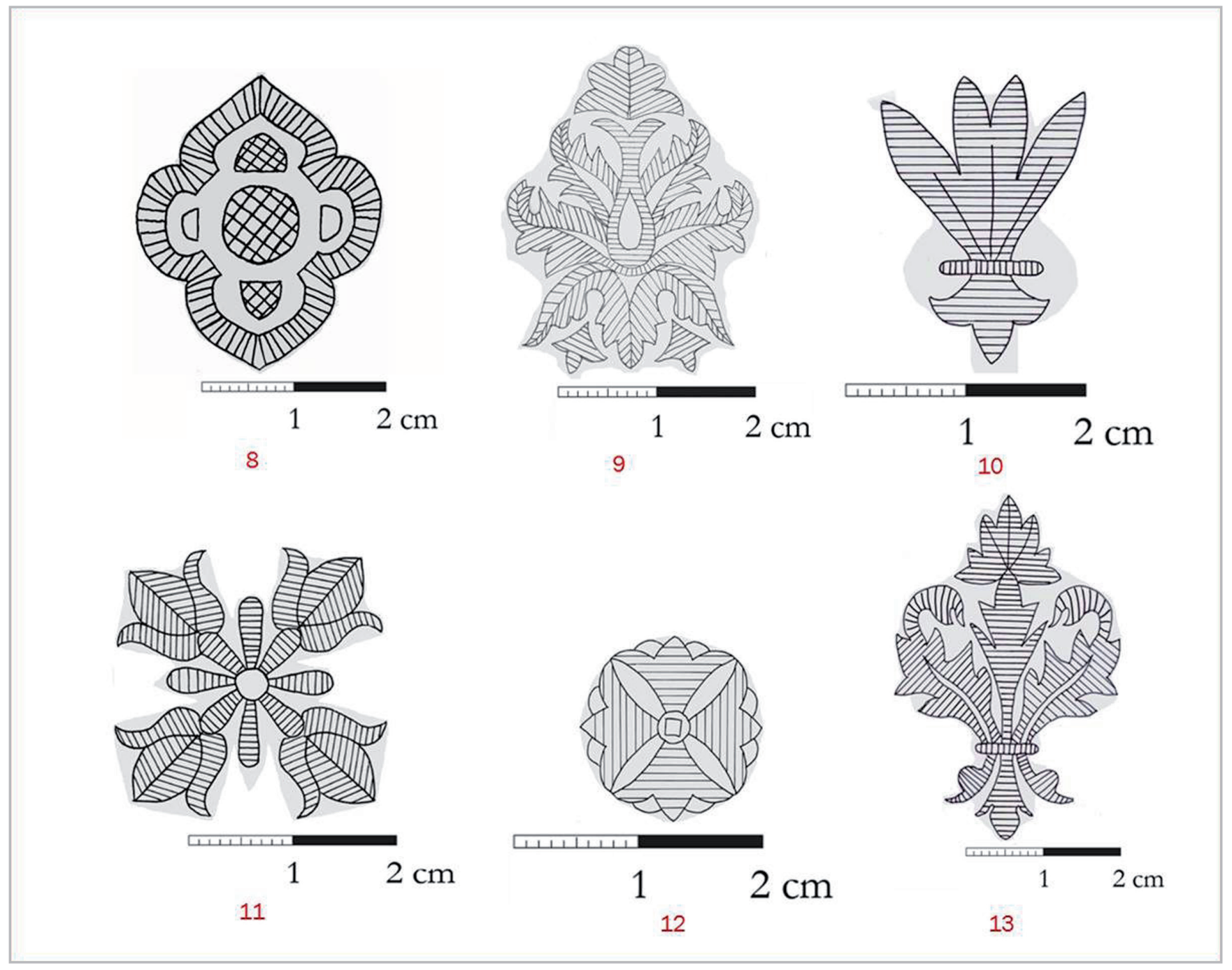

ornamentan Llanes (modelos 9, 10, 11, 12, 13). En el primero la ejecución de la policromía por Andrés de Espinosa, afamado pintor, está documentada por contrato (Echeverría y Martiarena 2006:24-26). En el segundo, Nodal plantea la atribución al mismo maestro (García 2015:6) a partir de su identificación de la misma matriz para uno de los motivos coincidentes.

\section{Conclusión}

Los nuevos casos presentados se ubican entre las obras más tempranas con brocado aplicado detectadas hasta ahora en Gipuzkoa: Oratorio de Loiola (1498-1512), Virgen de Zumaia (ca. 1500) y más tardío, san Martin de Azpeitia (1521).

El marco cronológico en el que se ubican las piezas guipuzcoanas con brocado conocidas hasta la fecha se extiende desde 1498 hasta 1537, es decir apenas cuarenta años de producción artística. Este periodo coincide con la transición y convivencia de dos estilos artísticos: el tardogótico y el primer renacimiento. Los brocados aplicados continuos que decoran los nuevos casos responden a modelos textiles derivados del "patrón de granada", extendido durante la etapa tardogótica. La irrupción del Renacimiento provoca la aparición de nuevos diseños, inspirados de la antigüedad clásica. En el caso de Gipuzkoa, en los retablos que han llegado hasta nuestros días, ello supondrá prácticamente el abandono de modelos continuos más gotizantes, con la excepción de Bidaurreta, donde conviven ambos. Además del cambio de modelos en el brocado, asistimos al cambio de técnicas polícromas, apareciendo el esgrafiado y abandonando progresivamente las aplicaciones. En los dos retablos más tardíos (La Piedad de Oñati y Altzaga), el brocado aplicado se limita a los motivos aislados salpicados.

La calidad de los retablos viene determinada en parte por la categoría de sus comitentes, relacionados con la corte y los centros de innovación artística. Personajes ilustres como Martín de Zurbano, Jofre de Sasiola o Juan López de Lazarraga, miembros del Consejo Real y secretario de la reina respectivamente, o el obispo Rodrigo de Mercado, han marcado de forma decisiva el programa y la estética de los retablos encargados (Azpeitia, Zumaia, Bidaurreta y La Piedad respectivamente). 
En cuanto a la procedencia de autores y estilos, la producción guipuzcoana está perfectamente enraizada en las corrientes artísticas predominantes de la época. Los puertos cantábricos eran la salida natural de la relación comercial de Castilla con Flandes, y Burgos era el centro neurálgico de esta actividad, de donde llegaban las novedades importadas de Europa central; al igual que numerosos maestros y artistas que acudían a la península atraídos por un periodo de bonanza y el gusto por lo nórdico (Gómez y Gómez 2005: 266-7). Así, dentro de este pequeño elenco, contamos con obras de importación, tales como la virgen de Zumaia y el retablo de Errenteria. A su vez, la influencia nórdica resulta patente en obras de factura local, como los retablos de Azpeitia, ejecutado por un maestro foráneo, y Zumaia, cuyas pinturas han tenido en algún momento atribuciones flamencas. Ya más avanzado el siglo XVI, las obras se emparentan con la producción del entorno burgalés, como deseaban los propios comitentes $^{[12]}$.

Sobre la relación entre los modelos de decoración de brocado aplicado que hemos ido desgranando, se pueden extraer varias conclusiones:

- Existen múltiples filiaciones entre motivos en diferentes retablos guipuzcoanos y entre estos y los territorios limítrofes de Bizkaia y Álava ${ }^{[13]}$, y los más lejanos de Burgos y Asturias. [figura 8].

- No todos los retablos guipuzcoanos presentan relación entre motivos. Así los motivos textiles de la Virgen y de san Miguel de Arrasate, no se han detectado hasta la fecha en ninguna otra obra. De la misma manera, los modelos de Errenteria, de procedencia bruselense, son estilísticamente diferentes y se asemejan a obras brabanzonas, como el retablo de Orduña.

- El marco geográfico es significativo a la hora de establecer filiaciones, y por el momento se han hallado semejanzas más allá de la comunidad del País Vasco, con modelos del entorno castellano, la más alejada en Toledo.

- La trama de filiaciones que se establece entre los retablos por coincidencia de motivos de brocado resulta extremadamente compleja:Azpeitia y Lekeitio se relacionan con 5 retablos; Zumaia, Loiola y Llanes con 4; Arrieta, Larrabetzu, Olano y Aspuru con 3. Bidaurreta solo presenta semejanzas con Arganzón y la Piedad de Oñati únicamente con Llanes (en el estado actual de la investigación).

- La semejanza entre modelos es de distinto orden. Así encontramos motivos que, a pesar de sus pequeñas diferencias, resulta evidente que han compartido la misma fuente, sea el propio textil, sea un grabado o cartón con el dibujo. Al mismo tiempo, vemos motivos idénticos, cuya semejanza nos ha llevado a plantear el uso de la misma placa o matriz para su realización, como es el caso de los retablos de Zumaia, Arrieta y Larrabetzu, con analogías importantes, que tal vez demuestren una filiación más profunda o una autoría compartida.

Las agrupaciones y filiaciones presentadas por el momento plantean más preguntas que respuestas. ¿Qué relación entre artistas y talleres hay en este grupo de obras? ¿Cuáles son los retablos o los artistas que marcaron el hito y posteriormente otros emularon? El marco apenas está apuntado y el campo abierto a próximas investigaciones que puedan aportar luz a este intrincado entramado de obras singulares. En esta época,

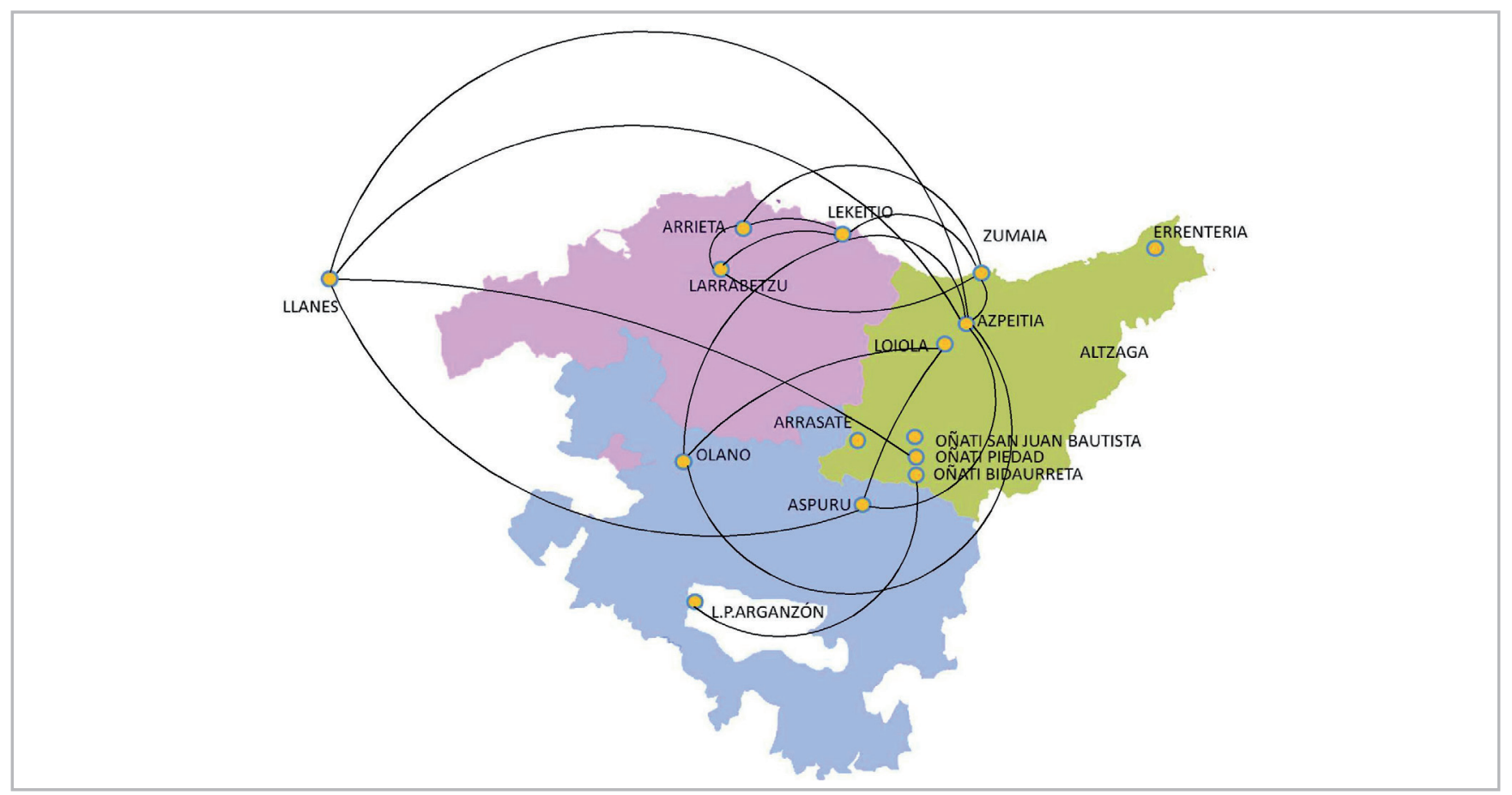

Figura 8.-Relación entre retablos a partir de los modelos de brocado aplicado. 
donde la documentación escrita conservada es escasa, el estudio de la técnica y la detección de modelos de brocado aplicado coincidentes pueden convertirse en una herramienta muy útil para el establecimiento de relaciones entre obras.

\section{Agradecimientos}

Queremos agradecer especialmente a J. de Miguel (Equipo 7) por los modelos mostrados de Lekeitio, Arrasate y Markina; a Camino Roberto por la información sobre el retablo de Llanes, a Teresa Gómez por los datos sobre el retablo de Toledo y a Ana Carrasson y Marisa Gómez por la ayuda prestada generosamente. Igualmente, señalar la contribución de las memorias inéditas de restauración de Aspuru (Petra coop.), Fontecha (Croma, S.C., Geroa S.C. y Trateggio S.C.) y Olano (Trateggio S.C.), que nos han ayudado en la consecución de esta investigación.

\section{Notas}

[1] Proyecto de investigación que analiza siete retablos esculpidos de origen brabanzón y seis de producción local del periodo tardogótico ubicados en el País Vasco. Una parte de este trabajo es accesible on line en Retablos esculpidos flamencos en España (Barrio, Berasain y Muñiz 2014).

[2] Proyecto de investigación dirigido por Muñiz en 2016-2017. Este trabajo ha servido igualmente para descartar la presencia de brocado aplicado en cuatro tallas de Malinas del Monasterio de Bidaurreta (tres con sello de garantía " $\mathrm{M}$ " y una con escudo de la villa) y en la escultura santa Ana Triple del convento de santa Clara de Elgoibar (castillo y mano de la marca de garantía de Amberes).

[3] El Grupo Europeo de Policromía en relieve ha sido creado en 2018 por una quincena de investigadores con la finalidad inicial de proponer una metodología común para la representación gráfica de modelos de brocado aplicado.

[4] La fecha relativamente tardía del retablo y el hecho de no haber podido probar a día de hoy su uso en este mueble litúrgico, podría poner en duda el cumplimiento de las condiciones de este contrato.

[5] Nos gustaría citar en este contexto los trabajos de R. García Ramos y E. Ruiz de Arcaute, que abordaron en estos años el estudio de esta técnica en España (García y Ruiz de Arcaute 1996).

[6] El retablo y el sepulcro del Obispo Zurbano son las primeras obras conservadas del patrimonio artístico de Gipuzkoa de las que se posee documentación. Corregimos la lectura del apellido que Arrazola interpretó como Pigmel.

[7] AHPG-GPAH, 2-0007, A, Fol. 281r-285r

[8] El redorado del retablo de Larrabetzu nos impide observar el colorido original.

[9] No se han realizado análisis de identificación de materiales, por lo que desconocemos si es el propio estaño lo que se observa u otra hoja metálica oxidada. Roberto ya había detectado ejemplos de brocados aragoneses bicolores (Roberto 2014:278).

[10] Muñiz plantea la posibilidad de que con ello se deseara crear un efecto que aumente la profundidad de las cajas.

[11] Barrón señala una casulla y una dalmática de la iglesia de san Cosme y san Damián de Burgos y un terno fúnebre de la iglesia de san Gil, que data en torno a 1520 (Barrón 2011:89).

[12] Sobre el retablo de Bidaurreta: "el cual dicho retablo llevando las medidas a Burgos fagase facer de muy buena mano e pintura" (Arrazola et al 1991:22).

[13] También entre retablos de la región que no abordamos aquí por no coincidir con obras guipuzcoanas. Entre los brocados continuos, Lekeitio comparte un motivo de patrón de granada con Aspuru; Arganzón uno de palmeta con Markina; el retablo mayor de Artziniega dos patrones de granada con el retablo de la Capilla de las Viejas en san Martín de Briviesca (Barrio y Equipo 7 Restauración S.L. 1999:53); el del santo Cristo de Artzeniega uno geométrico/vegetal con el retablo de la capilla Bardecí de Délica, dato señalado por García Ramos (Barrio 1999: 5). Entre los aislados, un clavel de Arganzón con Markina y Fontecha, una estrella con rayado paralelo de Arganzón con Olano, una estrella compartimentada de la Virgen del Socorro de Martioda con el retablo de la pasión de Délica y el retablo de Portugalete.

\section{Referencias}

ARRAZOLA, A. (1988, 1967). Renacimiento en Guipúzcoa, t. II Escultura. Donostia-San Sebastian: Departamento de Cultura, Gipuzkoako Foru Aldundia/Diputación Foral de Gipuzkoa.

ASTIGARRAGA, J. M. (coord.) (2000). San Juan Bautista de Mondragón-Arrasate. Una interesante e inacabada historia. Arrasate: Parroquia de san Juan. Ed. Parroquia de San Juan.

ARTELAN RESTAURACIÓN, S.L. (2000). Informe de Restauración del Retablo de la Capilla de la Piedad en la Iglesia Parroquial de San Miguel en Oñate". Inédito.

ARTELAN RESTAURACIÓN, S.L. (2003). Informe de Restauración del Retablo de San Miguel de Altzaga (Siglo XVI). Inédito.

BARRIO, J.A. (1999). El Retablo Mayor del Santuario de la Encina de Arceniega en Álava, Vitoria-Gasteiz: Iberdrola.

BARRIO, M. (2013). "Estudio técnico de la policromía en una perspectiva comparativa". En El retablo de la coronación de la Virgen. Parroquia de la Asunción de Errenteria/Ama Birjinaren koroatzearen erretaula. Errenteriako Jasokundeko parrokia, Barrio, M y Berasain, I. (coord.). Donostia-San Sebastián: Gipuzkoako Foru Aldundia/Diputación Foral de Gipuzkoa, 141-165.

BARRIO, M., BERASAIN, I., MUÑIZ, J. (2014). Retablos esculpidos flamencos en España http://retablos-flamencos.albayalde.org/ [ 
consulta: 28/02/2021].

BARRÓN, A. (2011). "Telas y bordados en Burgos durante el Renacimiento", Biblioteca. Estudio e Investigación, 26: 73-94.

BERASAIN, I. y BARRIO, M. (1998). "Aproximación a la policromía del Retablo de San Antón. Parroquia de San Pedro de Zumaia (Gipuzkoa)". En: Revisión del Arte del Renacimiento. Donostia-San Sebastián: Eusko Ikaskuntza-Sociedad de EstudiosVascos, Ondare. Cuadernos de Artes Plásticas y Monumentales 17: 377-387.

BONITO, R. (1995). “The Pomegranate Pattern in Italian Renaissance Textiles: Origins and Influence". En Proceedings of the Fourth Biennial Symposium of the Textile Society of America, September 22-24, 1994, Los Angeles, CA: Textile Society of America, 193-204 https:// digitalcommons.unl.edu/tsaconf/1042/[consulta: 28/2/2021]

BORGIOLI, C. (2011). “Tessuti e ricami. Progettualità ed esecuzione tra Medioevo e Rinascimento". En Chirurgia della creazione. Mano e arti visive, Ducci, A. Pisa: Felici Editore, 59-72.

CARRASSÓN LÓPEZ DE LETONA, A. ET AL. (2021) Propuesta metodológica para el examen, registro y representación gráfica de los brocados aplicados. Ge-Conservacion, 19(1). https://doi. org/10.37558/gec.v19i1.843.

ECHEVERRÍA, P. (1990). Policromía del Renacimiento en Navarra. Pamplona: Gobierno de Navarra.

ECHEVERRÍA, P. y MARTIARENA, X. (2006). Oñatiko Unibersitatearen Kaperako Erretaula: historia eta zaharberritzea/Retablo de la Capilla de la Universidad de Oñati: historia y restauración. Donostia-San Sebastián: Gipuzkoako Foru Aldundia/Diputación Foral de Gipuzkoa.

ECHEVERRÍA. P. y VÉLEZ, J.J. (2011). “Arte religioso en La Puebla de Arganzón, villa de los Condestables". En Los valles occidentales entre el Zadorra, el Ayuda y el Inglares. La villa de La Puebla de Arganzón. Catálogo Monumental. Diócesis de Vitoria. Tomo X, Tabar, F. (coord), Vitoria-Gasteiz: Fundación Caja Vital, 155 - 220.

GARCÍA, E. "El retablo de Llanes ya tiene firma". En La Nueva España 5/7/2015. 5-7 https://www.Ine.es/mas-domingo/2015/07/05/ restaurador-portico-gloria-asturiano-descubre-19773813.html [consulta: 28/2/2021].

GARCÍA, R. y RUIZ DE ARCAUTE, E. (1996) “Aproximación al brocado aplicado en España. Desarrollo y extensión". En XI Congreso de Conservación y Restauración de Bienes Culturales: Diputación Provincial de Castellón. Castellón de la Plana, 747-756.

GEELEN, I. y STEYAERT, D. (2011). Imitation and illusion: Applied Brocade in the Art of the Low Countries in the Fifteenth and Sixteenth Centuries. Brussels: Royal Institute for Cultural Heritage.

GÓMEZ ESPINOSA, T. y GÓMEZ GONZÁLEZ, M.L. (2005). “Policromía tardogótica española". En Actas del congreso internacional, Ao modo da Flandres: disponibilidade, innovaçao e mercado de arte a época dos decubrimentos (1415-1580), Universidad de Lisboa. García, B.J. y Grilo, F. (coords). Madrid: Fundación Carlos de Amberes, 265-278.
LIZARRALDE, J.A. (1926). Semblanza religiosa de la provincia de Guipúzcoa: ensayo iconográfico, legendario e histórico. Bilbao: Imprenta C. Dochau de Urigüen.

LOPETEGUI, P. (1945). “Cuestiones Loyoleas. El oratorio antiguo de la Casa de Loyola y el cuadro de la Anunciación - Una interesante relación de 1573, del P. Ubilla, rector del Colegio de Oñate". En Boletín de la Real Sociedad Vascongada de Amigos del País, año 1 , cuaderno 40, 365-371.

MUÑIZ, J. y YANIZ, S. (2020). San Martín de Arrieta. El retablo recuperado. Arrieta: Parroquia de san Martín Obispo.

MARTIARENA, X. (1980). Oratorio de la familia Loyola. Santuario de San Ignacio de Loyola. Azpeitia. Informe. Inédito.

MARTIARENA, X. ETAL (1991). Bidaurretako erretaula errenazentista: Zaharberritzea/Retablo renacentista de Bidaurreta: Restauración. Donostia-San Sebastián: Gipuzkoako Foru Aldundia/Diputación Foral de Gipuzkoa.

ODRIOZOLA, I. (1993). Iglesia parroquial de San Sebastián de Soreasu, de Azpeitia, Donostia-San Sebastián, Sociedad Guipuzcoana de Ediciones y Publicaciones.

ODRIOZOLA, L. (1998). Historia de Zumaia, Zumaiaren Historia. Zumaia: Zumaiako Udala.

ROBERTO, C. (2014). El brocado aplicadoen Aragón. Fuentes, tipologías y aspectos técnicos, Huesca: Instituto de Estudios Altoaragoneses.

RODRÍGUEZ, A. (2009). Análisis y clasificación de los brocados aplicados de los retablos de Guipúzcoa. Tesis doctoral, Bilbao: Universidad del País Vasco /Euskal Herriko Unibertsitatea.

WEISE, G. (1927). Spanische plastik aus sieben jahrhunderten, t. II, Reutlingen: Gryphius-Verlag.

\section{Autor/es}

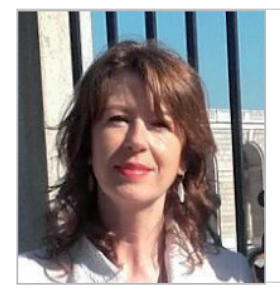

\section{Maite Barrio Olano}

mbarrio@albayalde.org

ALBAYALDE-conservatio

Directora de ALBAYALDE-conservatio desde 1989, empresa dedicada a la conservación del patrimonio cultural (www.albayalde.org). Trabaja principalmente para el sector público realizando numerosas intervenciones en el campo de la conservación preventiva y restauración; diseño de reservas de colecciones (Gordailua, Disseny HuB Barcelona, Museo de Colecciones Reales de Madrid); proyectos de investigación (POLICROM) y de difusión (Retablos Flamencos en España); proyectos europeos (Policromia) y de colaboración inter-institucional (Capilla Real de Granada). Licenciada en $\mathrm{H}^{\mathrm{a}}$ del Arte y Arqueología (Sorbona), licenciada en Conservación de 
Bienes Culturales (Panteón Sorbona), diplomada en Conservación y Restauración de Obras de Arte y Museología (UIA, Florencia), con estadía de formación en el Instituto Real de Patrimonio Artístico de Bruselas. En la actualidad desarrolla su labor principalmente en Gordailua, Centro de Colecciones Patrimoniales de Gipuzkoa, perteneciente a Diputación Foral.

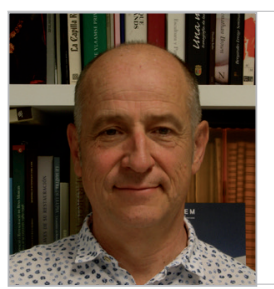

\section{Ion Berasain Salvarredi}

ionberasain@gmail.com

ALBAYALDE-conservatio

Co-fundador de ALBAYALDE-conservatio, empresa dedicada a la conservación del patrimonio cultural (www.albayalde.org). Trabaja principalmente para el sector público realizando numerosas intervenciones en el campo de la conservación preventiva y restauración; diseño de reservas de colecciones (Gordailua en Irún, Disseny Hub Barcelona, Museo de las Colecciones Reales de Madrid); proyectos de investigación (POLICROM) y de difusión (Retablos Flamencos en España); proyectos europeos (Policromia). Los estudios sobre retablos flamencos es una de sus líneas de trabajo destacadas. Licenciado en Historia del Arte por la Universidad Autónoma de Madrid, diplomado en Restauración (CEROA), diplomado en Conservación y Restauración de Obras de Arte y Museología (UIA, Florencia).

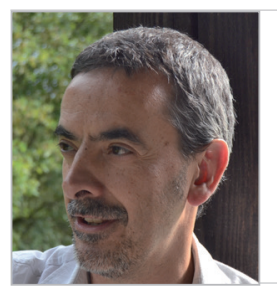

\section{Jesús Muñiz Petralanda}

jmpboreal@gmail.com

Conservador

Licenciado en Historia del Arte (Universidad de Salamanca, 1988) y Diplomado en Especialización en Documentación y Gestión del Patrimonio Histórico (Universidad de Deusto, 1999). Entre 2002 y 2013 fue Conservador del Museo Diocesano de Arte Sacro de Bilbao, institución que editó su estudio sobre La Escultura Mueble del Gótico Tardío en Bizkaia. Se ha especializado en el estudio del arte mueble de la Baja Edad Media en el País Vasco, tema de la tesis doctoral que prepara actualmente.

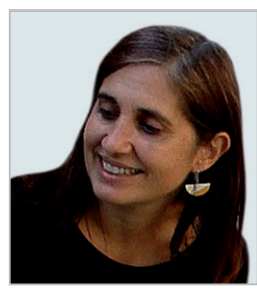

\section{Vera Aldabe Gil}

veraldabe@hotmail.com

Conservadora

Licenciada en Bellas Artes en la especialidad de Conservación y Restauración de obras de arte (Universidad del País Vasco, 1997) y formada en diseño gráfico, trabaja para el sector público y el privado, realizando funciones de conservación preventiva, restauración, gestión de documentación y manipulación de material gráfico. Ha colaborado en la restauración de obras como el Retablo de la Coronación de la Virgen de Rentería, el Retablo de los Santos de Covarrubias, o la Tabla votiva de Juan Martínez de Mendaro de Zumaia, todas ellas de origen flamenco. También ha participado en proyectos de difusión del patrimonio como la web Retablos flamencos en España.

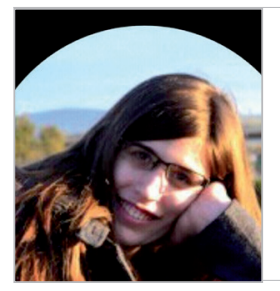

Iratxe Colado García

ircoga_90@hotmail.com

Estudiente de la Universidad del País Vasco

Licenciada en Bellas Artes en la Universidad del País Vasco, especialidad Conservación Restauración de Bienes Culturales. Actualmente cursando el Máster de Conservación y Exhibición en Arte Contemporáneo (CYXAC) en la misma universidad. Ha realizado trabajos para diversos organismos, así como prácticas en el Museo de BBAA de Bilbao, siendo becaria de Restauración en Gordailua, centro de colecciones patrimoniales en 2019-2020.
Artículo enviado el 18/03/2021 Artículo aceptado el 28/05/2021

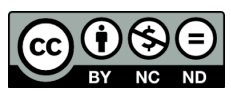

https://doi.org/10.37558/gec.v19i.976 